\title{
Ion-Ion Reactions in the Gas Phase: Proton Transfer Reactions of Protonated Pyridine with Multiply Charged Oligonucleotide Anions
}

\author{
William J. Herron, Douglas E. Goeringer, and Scott A. McLuckey \\ Chemical and Analytical Sciences Division, Oak Ridge National Laboratory, Oak Ridge, Tennessee, USA
}

Isolated triply and doubly charged anions of the single-stranded deoxynucleotide $5^{\prime}$ $d(\mathrm{AAAA})-3^{\prime}$ were allowed to undergo ion-ion proton transfer reactions with protonated pyridine cations within a quadrupole ion trap mass spectrometer. Sufficiently high ion number densities and spatial overlap of the oppositely charged ion clouds could be achieved to yield readily measurable rates. Three general observations were made: (1) the ion-ion reaction rate constants were estimated to be $10^{-(7-8)} \mathrm{cm}^{3} \mathrm{ion}^{-1} \mathrm{~s}^{-1}$; (2) the ion-ion reaction rates were found to be dependent on the reactant ion number density, which could be controlled by both the reactant ion number and the pseudopotential well depth, and (3) very little fragmentation, if any, was observed, as might normally be expected with highly exothermic proton transfer reactions. () Am Soc Mass Spectrom 1995, 6, 529-532)

$\mathrm{T}$ The gas phase ion chemistry of multiply charged biological polymers [1-5], such as oligonucleotides and proteins, is a new and growing area of research. Understanding the gas phase chemistry of these species is important both to obtain information on ion mass, structure, and reactivity and to determine the relationship between gas phase and condensed phase structure and reactivity. Gas phase ion chemistry studies to date have principally emphasized unimolecular fragmentation that follows some form of activation [6], and ion-molecule chemistry, which primarily involves proton transfer and $H / D$ exchange reactions [7-12]. The experiments described here constitute an important step in understanding the ion-ion chemistry associated with the reactions of multiply charged ions with oppositely charged ions in the gas phase.

Studies of gas phase ion-ion reactions of singly charged species date back to very early mass spectrometry experiments [13-18], whereas those that involve multiply charged ions that react with oppositely charged species were reported only recently [18-21]. In studies that involve large multiply charged ions, Loo et al. $[20,21]$ allowed a mixture of ionic reactants of opposite polarities to react at near atmospheric pressure. Although these studies were illuminating, definitive conclusions were sometimes difficult to draw due to a mixture of products that arises from a mixture

Address reprint requests to Dr. Scott McLuckey, Chemical and Analytical Sciences Division, Oak Ridge National Laboratory, Oak Ridge, TN 37831-6365. of reactants. For this reason we have designed an experiment to isolate a single pair of reactants to clearly define the parent-product relationship.

Pyridine vapor was leaked into the vacuum chamber and ionized to its radical cation by an electron beam directed radially into the quadrupole ion trap through a hole in the ring electrode. The pressure of neutral pyridine $\left(1-3 \times 10^{-7}\right.$ torr) was adjusted to allow for efficient production of protonated pyridine via self-chemical ionization. Essentially all of the radical cation was converted to protonated species within $10 \mathrm{~ms}$.

Anions of the single-stranded deoxynucleotide $5^{\prime}$ $d(\mathrm{AAAA})-3^{\prime}\left[d\left(\mathrm{~A}_{4}\right)\right]$ [22] were electrosprayed out of $25-\mathrm{pmol} / \mu \mathrm{L}$ solutions ( $>90 \%$ methanol-water) at flow rates of $0.25-0.5 \mu \mathrm{L} / \mathrm{min}$ through a $120-\mathrm{mm}$-i.d. stainless steel needle. The homemade electrospray source $[4,5,7,8,22]$ was coupled to a Finnigan-MAT (San Jose, CA) ion trap mass spectrometer [23, 24] quadrupole ion trap. (Although quadrupole ion traps have demonstrated the capacity to trap positive and negative ions simultaneously [25-27], other ion trapping devices such as the Fourier transform ion cyclotron resonance mass spectrometer may also simultaneously trap positive and negative ions [28, 29].) The triply charged anions $d\left(\mathrm{~A}_{4}\right)^{3-}$ and doubly charged anions $d\left(\mathrm{~A}_{4}+\mathrm{H}\right)^{2-}$ were used as reactants in separate experiments.

The multiply charged anions were isolated prior to cation formation. Protonated pyridine served as the cationic reactant. The anions and cations were stored simultaneously for up to $1 \mathrm{~s}$. The reaction was moni- 
tored both by the loss of parent ions and the appearance of product anions.

Sequential proton transfers could be observed either by isolation of the anionic products of the first ion-ion reaction and further reaction with additional cations formed by a subsequent electron pulse or by using a single extended electron ionization pulse. Figure 1 illustrates stepwise ion-ion proton transfer reactions. In the experiment that gave rise to Figure $1 \mathrm{a}$, isolated triply charged $d\left(\mathrm{~A}_{4}\right)^{3-}$ anions within a quadrupole ion trap mass spectrometer were allowed to react with protonated pyridine cations for $1 \mathrm{~s}$. The spectrum indicates that some of the $d\left(\mathrm{~A}_{4}\right)^{3-}$ anions underwent ion-ion proton transfer (1-ms electron pulse, 1000-ms storage) to form doubly charged $d\left(\mathrm{~A}_{4}+\mathrm{H}\right)^{2-}$ products. Contributions from competitive ion-molecule reactions, which arise from adventitious acidic neutrals in the vacuum system and produce the doubly charged $d\left(\mathrm{~A}_{4}+\mathrm{H}\right)^{2-}$ product, have not been subtracted and account for up to $20 \%$ of the doubly charged product ion intensity. Figure $1 \mathrm{~b}$ shows the negative ion spectrum after the doubly charged $d\left(\mathrm{~A}_{4}+\mathrm{H}\right)^{2-}$ products from the first ion-ion reaction were isolated and allowed to undergo a second ion-ion proton transfer (3-ms electron pulse, 1000-ms storage) to form singly charged $d\left(\mathrm{~A}_{4}+2 \mathrm{H}\right)^{1-}$. Contributions from competitive ion-molecule reactions that produce the singly
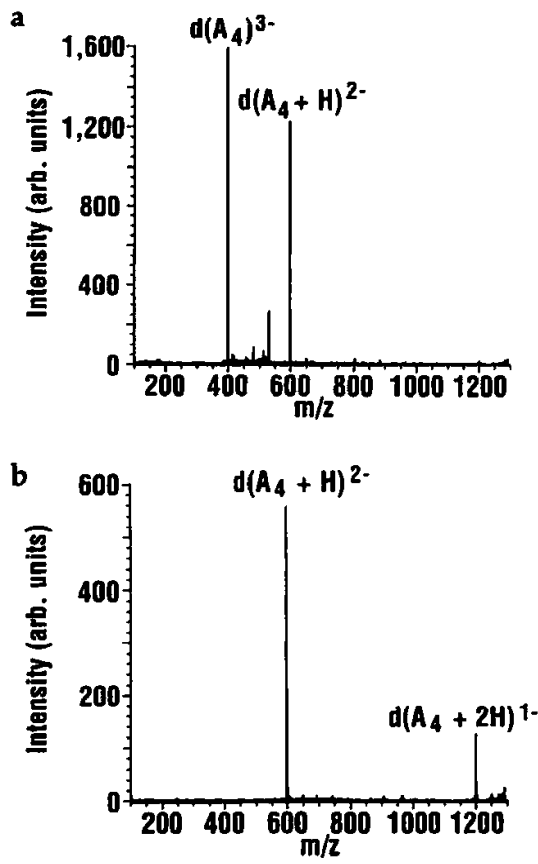

Figure 1. Isolated multiply charged oligonucleotide anions were allowed to react with protonated pyridine cations for $1 \mathrm{~s}$ within a quadrupole ion trap mass spectrometer. The isolated triply charged reactant anions $d\left(\mathrm{~A}_{4}\right)^{3-}$ (a) undergo ion-ion proton transfer with protonated pyridine to form doubly charged product anions $d\left(\mathrm{~A}_{4}+\mathrm{H}\right)^{2-}$ and (b) isolated doubly charged product anions $d\left(\mathrm{~A}_{4}+\mathrm{H}\right)^{2-}$ from the first ion-ion reaction, undergo ion-ion proton transfer with protonated pyridine to form singly charged product anions $d\left(\mathrm{~A}_{4}+2 \mathrm{H}\right)^{1-}$. charged $d\left(\mathrm{~A}_{4}+\mathrm{H}\right)^{2-}$ product were not observed over the time scale of the experiment. Note that for the same reaction time, a significantly greater fraction of the triply charged parent ion was converted to the doubly charged product than was observed for the analogous reaction of the doubly charged parent that reacted to form the singly charged product. This observation was made despite the longer ionization time (larger number of positive reagents ions) used in the latter experiment.

The rates of the ion-ion proton transfer reaction were determined by monitoring the loss of the parent anion as a function of time by using an excess of positive ions so that the anion decay would follow pseudo-first-order kinetics. The reaction rate was determined from a linear fit of the natural log of the normalized ion intensity versus reaction time. Each line was typically made up to 5-7 points, where each of these points was an average of 50 scans. All rate measurements were made over short reaction times $(<200 \mathrm{~ms})$, where ion-molecule contributions to the rate measurements were too small to be observed. We observed that the rates of ion-ion reactions were dependent on the duration of the ionization pulse. The rates of the reactions, however, were observed to level off beyond $10 \mathrm{~ms}$. It is likely that this "maximum rate" was caused by filling the trap to its maximum positive ion number density.

The rate of the reaction also was observed to be affected by the $q$ value $[23,24]$ at which the positive ions were stored. The depth of the pseudopotential well in which ions are stored is a function of the $q$ value. The largest number density for an ion population of a given mass-to-charge ratio (i.e., fastest rate) is predicted to occur near a $q$ value of 0.78 [24]. Measurements of the relative rates of the reaction at various $q$ values, with the same ionization time, showed a maximum around $q=0.80$. The measured rate varied by a factor of 2 across the range of $q$ values sampled (0.44-0.88).

The ion number density for the cationic reactant $(m / z=80)$ at a $q$ value of 0.55 , as approximated by the Dehmelt pseudopotential well model, is $1.3 \times 10^{8}$ ion $/ \mathrm{cm}^{3}[23,24]$. This value, which is expected to estimate the actual ion density within an order of magnitude, can be used in conjunction with the measured reaction rate to estimate reaction rate constants. An ion number density of $1.3 \times 10^{8}$ ion $/ \mathrm{cm}^{3}$ and the experimentally determined rate at a $q$ value of 0.55 for $d\left(\mathrm{~A}_{4}\right)^{3-}$ that undergoes proton transfer of $17 \pm 2 \mathrm{~s}^{-1}$, yield a rate constant of $1.3 \pm 0.2 \times 10^{-7} \mathrm{~cm}^{3}$ ion $^{-1}$ $\mathrm{s}^{-1}$. This value is comparable to rate constants reported for other ion-ion reactions [13-18]. A comparison of the rates for $d\left(\mathrm{~A}_{4}\right)^{3-}$ and $d\left(\mathrm{~A}_{4}+\mathrm{H}\right)^{2-}$ that undergo ion-ion proton transfer reactions under similar conditions shows a fivefold reduction in the rate for the less highly charged species; hence, there is a correspondingly smaller rate constant $\left(k \simeq 2.6 \pm 0.4 \times 10^{-8}\right.$ $\mathrm{cm}^{3}$ ion $^{-1} \mathrm{~s}^{-1}$ ). 
The ratio of the reaction rates for the triply charged anions and doubly charged anions is unexpectedly high. Based solely on Coulombic attraction, a ratio of 1:2:3 might be expected for the relative reaction rates of the singly, doubly, and triply charged parent anions. For example, the rate constant for the electron transfer ion-ion reaction of $\mathrm{He}^{2+}$ and $\mathrm{H}^{-}$exceeds the rate of $\mathrm{He}^{+}$reaction with $\mathrm{H}^{-}$by a factor of 2 [18]. A contributing factor to the apparent enhancement in the reaction rate of the triply charged anions relative to the doubly charged anions may arise from the different well depths experienced by the anion reactants. In these studies, the triply charged anions experience a greater well depth than the doubly charged anions [23, 24] and therefore are expected to occupy a smaller volume at the center of the trap. This could result in a better spatial overlap between the anion and cation ion clouds that yields an effective higher charge density for the triply charged anion than for the doubly charged anion.

No attempt was made in these studies to characterize the internal or translational energies of the reactant ions, but the presence of a light bath gas tends to thermalize ion populations in the quadrupole ion trap. The internal energies of the ion are expected to approach the temperature of the bath gas, based upon the observed lifetimes of noncovalently bound species stored under the conditions used here [30-33]. Translational energies are also expected to be low compared with the relative translational energy of the collision partners arising from their Coulombic attraction.

These reactions are expected to be highly exothermic because the reaction enthalpies are determined by the difference between the proton affinity of pyridine and the gas phase acidities of multiply charged anion products. The latter have not been measured, but are expected to exceed $320 \mathrm{kcal} / \mathrm{mol}$ (based on values of highly acidic neutrals [34]), which suggests that the reactions are exothermic by at least $100 \mathrm{kcal} / \mathrm{mol}$.

Interestingly, very little fragmentation, if any, is observed as a result of these reactions, despite the high exothermicity associated with partial neutralization. A comparison of the tandem mass spectra of the doubly charged product anion formed by ion-ion reactions with protonated pyridine and by ion-molecule reactions with trifluoroacetic acid (McLuckey, S. A., unpublished data) were found to be indistinguishable. These experiments indicate that the structures of the two ions formed by different methods are similar, at least by the time they are interrogated by collisional activation. Although the tandem mass spectrometry experiment is not expected to be sensitive to the degree of internal energy present in the product upon its formation, the lack of fragmentation upon formation suggests that the exothermicity of the ion-ion reaction is not efficiently partitioned into the internal modes of the product. This observation might be taken to imply that the collision complex is short lived such that the high relative translational energy of the reactants, de- rived from their Coulombic attraction, largely remains as translation in the products.

Although much is left to be learned about the dynamics that govern these reactions, it is significant that the rate constants are large and that sufficiently high ion number densities and spatial overlap of the oppositely charged ion clouds could be achieved in a quadrupole ion trap to yield readily measurable rates. Additionally, two general observations were made: (1) the ion-ion reaction rates were found to be dependent on the reactant ion number density, which could be controlled by both the reactant ion number and the pseudopotential well depth, and (2) very little fragmentation, if any, was observed, as might normally be expected with highly exothermic proton transfer reactions. A wide variety of other ion-ion reaction types have yet to be investigated. Given the wide range of ionic species that can be formed in the gas phase and the remarkable flexibility of ion trapping instruments in manipulating ions, gaseous ion-ion chemistry is likely to grow as an area for research in the characterization of large multiply charged polymers.

\section{Acknowledgments}

Deoxynucleotides were prepared by Dr. Mitchel J. Doktycz. This work was supported by the National Institutes of Health under grant R01GM45372. Oak Ridge National Laboratory is managed for the U.S. Department of Energy under contract DE-AC05$84 \mathrm{OR} 21400$ by Martin Marietta Energy Systems, Inc. $\mathrm{WJH}$ acknowledges support through an appointment to the Oak Ridge National Laboratory Postdoctoral Research Associates Program administered jointly by the Oak Ridge Institute for Science and Education and Oak Ridge National Laboratory.

\section{References}

1. Yamashita, M.; Fenn, J. B. J. Phys. Chem. 1984, 88, 4451-4459.

2. Bruins, A. P.; Covey, T. R.; Henion, J. D. Anal. Chem. 1987, 59, 2642-2646.

3. Smith, R. D.; Loo, J. A.; Loo, R. R. O.; Busman, M.; Udseth, H. R. Mass Spectrom. Rev. 1991, 10, 359-451.

4. McLuckey, S. A.; Van Berkel, G. J.; Goeringer, D. E.; Glish, G. L. Anal. Chem. 1994, 66, 689A-695A.

5. McLuckey, S. A.; Van Berkel, G. J.; Goeringer, D. E.; Glish, G. L. Anal. Chem. 1994, 66, 737A-743A.

6. Smith, R. D.; Loo, J. A.; Edmonds, C. G.; Barinaga, C. J.; Udseth, H. R. Anal. Chem. 1990, 62, 882-899.

7. McLuckey, S. A.; Van Berkel, G. J.; Glish, G. L. J. Am. Chem. Soc. 1990, 112, 5668-5670.

8. McLuckey, S. A.; Glish, G. L.; Van Berkel, G. J. Anal. Chem. 1991, 63, 1971-1978.

9. Blades, A. T.; Jayaweera, P.; Ikonomou, M. G.; Kebarle, P. Int. J. Mass Spectrom. Ion Processes 1990, 101, 325-336.

10. Loo, R. R. O.; Loo, J. A.; Udseth, H. R.; Fulton, J. L.; Smith, R. D. Rapid Commun. Mass Spectrom. 1992, 6, 159-165.

11. Suckau, D.; Shi, Y.; Beu, S. C.; Senko, M. W.; Quinn, J. P.; Wampler, F. M., III; McLafferty, F. W. Proc. Natl. Acad. Sci. USA 1993, 90, 790-793. 
12. Winger, B. E.; Light-Wahl, K. J.; Rockwood, A. L.; Smith, R. D. J. Am. Chem. Soc. 1992, 114, 5897-5898.

13. Moseley, J. T.; Olson, R. E.; Peterson, J. R. Case Studies in Atomic Physics, Vol. 5; North-Holland: Amsterdam, Netherlands, 1975; pp 1-45.

14. Smith, D.; Adams, N. G. In Physics of Ion-Ion and Electron-lon Collisions; Brouillard, F.; McGowan, J. W., Eds.; Plenum: New York, 1981; pp 501-531.

15. Bates, D. R. In Advances in Atomic and Molecular Physics, Vol. 20; Bates, D.; Bederson, B., Eds.; Academic: New York, 1985; pp 1-40.

16. Dolder, K. T. In Physics of Ion-Ion and Electron-Ion Collisions; Brouillard, F.; McGowan, J. W., Eds.; Plenum, New York, 1981; pp 373-413.

17. Mahan, B. H. Adv. Chem. Phys. 1971, 23, 1-40.

18. Dolder, K.; Peart, B. Rep. Prog. Phys. 1985, 48, 1283-1332.

19. Salzborn, E. I. Phys. (Panis) C1 1989, 50, 207-228.

20. Loo, R. R. O.; Udseth, H. R.; Smith, R. D. I. Phys. Chem. 1991, 95, 6412-6415.

21. Loo, R. R. O.; Udseth, H. R.; Smith, R. D. J. Am. Soc. Mass Spectrom. 1992, 3, 695-705.

22. McLuckey, S. A.; Van Berkel, G. J.; Glish, G. L. I. Am. Soc. Mass Spectrom. 1992, 3, 60-70.
23. March, R. E.; Hughes, R. J. Quadrupole Storage Mass Spectrometry; Wiley: New York, 1989.

24. Todd, J. F. J.; Lawson, G.; Bonner, R. F. In Quadrupole Mass Spectrometry and its Applications; Dawson, P. H., Ed.; Elsevier Scientific: New York, 1976.

25. Schermann, J. P.; Major, F. G. Appl. Phys. 1978, 16, 225-230.

26. Mather, R. E.; Todd, J. F. J. Int. J. Mass Spectrom. Ion. Phys. 1980, 33, 159-165.

27. Williams, J. D.; Cooks, R. G. Rapid Commun. Mass Spectrom. $1993,7,380-382$.

28. Gorshkov, M. V.; Guan, S.; Marshall, A. G. Rapid. Commun. Mass Spectrom. 1992, 6, 166-172.

29. Wang, Y.; Wanczek, K. P. Rev. Sci. Instrum. 1993, 64, 883-889.

30. McLuckey, S. A.; Glish, G. L.; Asano, K. G.; Bartmess Int. J. Mass Spectrom. Ion Processes 1991, 109, 171-186.

31. McLuckey, S. A.; Ramsey, R. S. J. Am. Soc. Mass Spectrom. 1994, 5, 324-327.

32. Doktycz, M. J.; Habibi-Goudarzi, S.; Mcluckey, S. A. Anal. Chem. 1994, 66, 3416-3422.

33. Herron, W. J.; Goeringer, D. E.; McLuckey, S. A. Proceedings of the 42nd ASMS Conference on Mass Spectrometry and Allied Topics; Chicago, IL, May 29-June 3, 1994; p. 213.

34. Harrison, A. G. Chemical Ionization Mass Spectrometry, 2nd ed.; CRC: Boca Raton, FL, 1993; Chap. 2. 